\title{
BIG FIVE PERSONALITY TRAITS IN LEARNING COMPLEX INFORMATION SYSTEMS: A CASE STUDY
}

\author{
Bih-Ru Lea, Missouri University of Science \& Technology, leabi@mst.edu \\ Katherine Yu, University of Missouri - Columbia, kayn9h@missouri.edu \\ Amanda Engelke, Rolla High School, aengelke@rolla.k12.mo.us \\ Carol Koob, Truman State University, koobcarol@gmail.com
}

\begin{abstract}
This research explores the influence of personality traits on the performance of learning a complex information system. The personality traits studied are conscientiousness, neuroticism, extraversion, openness, and agreeableness and the complex information system is represented by an Enterprise Resource Planning (ERP) System. The preliminary results indicate Openness, the interaction of Openness and Agreeableness, the interaction of Openness, Agreeableness, and Conscientiousness, the interaction of Openness, Agreeableness, and Extraversion, and the interaction Openness and Extraversion are statistically significant on influencing ERP learning performance.
\end{abstract}

Keywords: Personality traits, Information Systems, ERP, Learning Performance

\section{INTRODUCTION}

Enterprise Resource Planning (ERP) systems are large-scale, complex, heavily procedural-, process-, and detailoriented computer systems (Kumar \&Van Hillegersberg, 2000; Shtub, 2001; Tenhiala \& Helkio, 2015). Due to their intricate nature, it can be challenging for beginners to familiarize themselves with and become adept at utilizing ERP systems. The lack of ERP-relevant technical, analytical and business process management skills in IT professionals and end-users can hinder the adoption and successful use of such systems (Sumner, et al., 2006). As a result, the need for a skilled ERP workforce put pressure on universities to educate students with ERP knowledge (Charland, et. al., 2015).

Finding an efficient mechanism for universities to educate students with ERP knowledge and for various companies to recruit talented and qualified workers has presented itself as a difficult task. Although a multitude of factors contributes to the success of students learning ERP systems, the ability to identify factors with the highest correlation to success, or particular clusters of these factors could be a significant advancement. As personality traits are perceived to be correlated with job performance, companies often utilize personality assessment in their quest for skilled IT workers (Lui, et. al., 2008). This study aims to determine the best way to measure aptitude for the field of ERP. Specifically, our goal was to determine if there is an individual personality trait or an ideal combination of the Big Five personality traits that predict high success within ERP systems.

\section{LITERATURE REVIEW}

\section{Challenges in Complex Information System Education}

ERP system is "an integrated system where a unique database provides flow for information continuously and consistently for the entire company" (Wadate, 2014; Klaus \& Gable, 2000) and becomes a strategic tool that helps an organization to gain a competitive edge through integrating all business processes and optimizing the available resources available. As an ERP system integrates all information systems across an organization, it creates an interconnection between functions and various processes (Barki \& Pinsonneault 2002) and that contributes to the complexity in learning and operating the system.

The widespread implementation of ERP systems over the last two decades has led to the challenge for companies to recruit a skilled ERP workforce and for universities to educate graduates with ERP knowledge (Charland, et al., 2015). 


\section{Issues in Information Systems}

Volume 20, Issue 4, pp. 107-115, 2019

As most IT failures stem from a lack of user acceptance rather than poor technical quality (Nelson and Cheney, 1987), the successful implementation of ERP systems requires effective, reinforced and updated training of personnel (Markus et al., 2000; Gargeya and Brady, 2005). Because of the complexity of an ERP system, the learning curve is steep and has become a challenge for both educators and learners. Furthermore, the steep learning curve and a heavy infrastructure investment needed by the educational institutes result in few academics who have intimate knowledge of the strengths and weaknesses of ERP (Becarra-Sanchez, et. al., 2002) and that had limited the ability of the U.S. universities in addressing this industry critical need. Such shortage had led to IT outsourcing that hinders our nation's competitiveness and economy.

Léger (2006) and Seethamraju (2011) believe that the challenge for students to learn the business process and ERP software in the classroom is the lack of knowledge and understanding about real-world business processes as well as the limited IT skills to operate an ERP software application. Boyle and Strong (2006) recommend that in order to be successful in learning an EPR system, a student needs to possess not only technical skills such as operating system, system analysis or data management, but also technology management knowledge, business functional knowledge, interpersonal skills and teamwork skills. Researchers have observed correlations between personality traits and one's interpersonal skills and teamwork skills (Riggio, 1986; Wodarski, et al., 1988; Neuman \& Wright, 1999). As a result, personality traits and assessment are often utilized by companies in their quest for skilled IT workers (Lui, et. al., 2008).

\section{Personality Traits and Academic Learning Performance}

Since the late twentieth century, psychologists have used the Big Five Trait model to assess and describe people's unique personality styles. The traits included are conscientiousness, neuroticism, extraversion, openness, and agreeableness. Each trait is presented as a spectrum, on which subjects can score moderately or to either extreme. Conscientiousness is a measure of how organized, disciplined, and achievement-oriented a person is (Komarraju, et. al., 2011). People who are highly conscientious have good self-control, determination, purposefulness, dependability, and the will to achieve (Grehan, et al., 2011). Neuroticism is known as the degree of emotional stability, anxiety, and impulse control a person has. Extraversion refers to a person's degree of sociability, talkativeness, and assertiveness (Komarraju, et. al., 2011). People who are highly extraverted will have a tendency to be cheerful, assertive, and social (Grehan, et al.,, 2011). Openness is the measure of a person's intellectual curiosity and preference for novelty and variety. When a person is highly open they are receptive to new ideas, attentive to inner feelings, and prefer varied sensations (Grehan, et al., 2011). The last trait, agreeableness, is characterized by how helpful, cooperative, and sympathetic a person is. Researchers further classify Big Five personality traits into higher-order factors such as stability (Neuroticism, Agreeableness, Conscientiousness) and plasticity (Extraversion, Openness) (Buruk, et al., 2017; Davies, 2014; DeYoung, 2006; DeYoung, et al., 2002).

Meta-analyses have shown a connection between personality traits and academic success. For example, certain personality traits have been linked to learning styles such as deep and shallow processing. Individuals who are highly conscientiousness, open, extraverted, and emotionally stable tend to process information with the goal of mastery through deep understanding and long-term retention as opposed to the shallow goal of performing well on assessments. (Furnham, 1996; Komarraju et. al., 2011). Conscientiousness, openness, and agreeableness each show a positive relationship to academic success (Paunonen \& Ashton, 2001; Laidra et. al., 2007) with conscientiousness having the highest relation and being the strongest predictor (Poropat, 2009). Meanwhile, neuroticism and extraversion were negatively related to success in academics (Chamorro-Premuzic \& Furnham, 2003; Nguyen et. al., 2005; O'Connor \& Paunonen, 2007; De Raad \& Schouwenburg, 1996). Agreeableness and openness were also shown to have an impact on fostering collaborative learning (Komarraju et. al., 2011).

Although personality traits \& academic performance are clearly linked, learning styles and academic environment may complicate how these connections manifest. When in specific academic settings, the impact of certain traits on academic success varies. In learning environments and contexts that require knowledge acquisition, conscientiousness was shown to be the best predictor of academic success. However, in graduate settings that tend to emphasize skill acquisition and application, neuroticism was shown to be linked to increased performance (Ferguson, 2014).

\section{RESEARCH QUESTIONS AND METHODOLOGY}

As personality traits are perceived to be correlated with learning performance (Komarraju et al., 2011; Poropat, 2009; Laidra et all, 2007; Chamorro-Premuzic \& Furnham, 2003; Furnham, 1996) and job performance (Lui, et. al., 2008), 


\section{Issues in Information Systems \\ Volume 20, Issue 4, pp. 107-115, 2019}

the objective this research is to seek insights if there is an individual personality trait or an ideal combination of the Big Five personality traits that predict success in learning ERP systems and concepts.

The success in learning ERP concepts and concepts is measured by course grade. The Big Five personality traits are conscientiousness, neuroticism, extraversion, openness, and agreeableness. The Mini-IPIP. This twenty-item assessment is an abbreviated version of the original International Personality Item Pool (IPIP) which contains only four questions to assess each trait. Studies conducted to test the reliability and validity of the Mini-IPIP have confirmed both; the Mini-IPIP is recommended as an efficient yet effective personality assessment tool (Donnellan, et al., 2006).

Data were collected from two universities located in the Midwest of the United States over three semesters: Fall 2016, Spring 2017 and Fall 2018. Among a total of 232 students with valid responses, female, male, and no disclosure students are $35.3 \%, 52.6 \%$, and $12 \%$ respectively. Graduate students and undergraduate students are $66 \%$ and $25 \%$ respectively. About $50 \%$ of participants are white or Caucasian, $28 \%$ are Asian or Pacific Islander, $7 \%$ are Black or African American, $1 \%$ is Hispanic or Latino, and about $14 \%$ are other or non-disclosure. Participants indicate that English is their first language, native language, primary language are $35 \%, 15 \%$, and $15 \%$ respectively. About $19 \%$ of participants speak English fluently and about 3\% speaks at the elementary level. Figure 1 provides a summary of participant information.
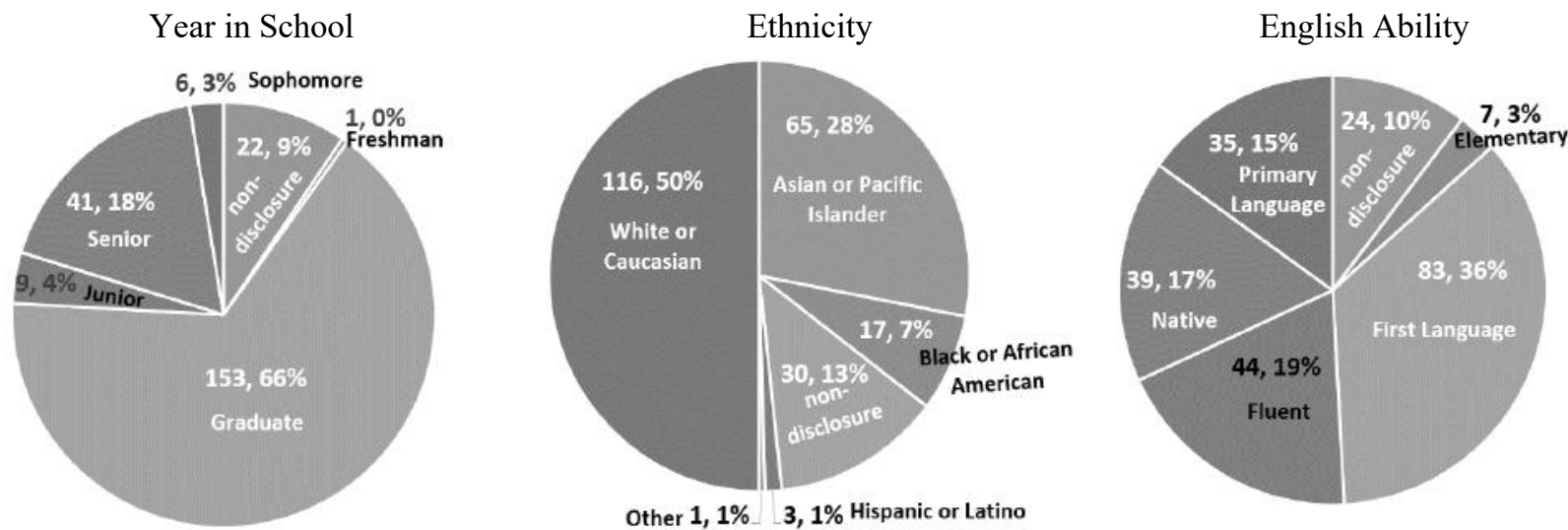

Figure 1. Year in School, Ethnicity, and English Ability Information among Participants

\section{RESULTS AND DISCUSSIONS}

Univariate Analysis of Variance (ANOVA) analysis was conducted and results that were summarized in Table 1. The main effect of Openness, the interaction of Openness and Agreeableness, the interaction of Openness, Agreeableness, and Conscientiousness, the interaction of Openness, Agreeableness, and Extraversion are statistically significant on influencing ERP learning performance at $\alpha=0.05$ level. The interaction of Openness and Extraversion is statistically significant on influencing ERP learning performance at $\alpha=0.10$ level.

With the complexity of ERP systems and students' lack of knowledge and understanding about real-world business processes, individuals with a higher degree of Openness trait could have a better chance to succeed as they tend to be more willing to accept theories and opinions from different perspectives, to not be limited by mental sets and be more willing to try different approaches, to see difficult tasks as challenges rather than obstacles, and more open to receive help from different people. However, the results indicate that Openness alone may not be sufficient as evident by its interaction effects with agreeableness, extraversion, and conscientiousness.

\section{Openness and Agreeableness}

As an ERP system integrates and coordinates business processes across various functional areas including manufacturing, accounting, marketing, sales, logistics, and human resources, the researchers believe that individuals with both Openness and Agreeableness personality traits are likely to perform better. The two aspects of individuals with a higher degree of agreeableness are compassion and politeness, so those individuals are more likely to coordinate their goals with those of others (DeYoung, 2006, 2015, 2018), are more willing to compromise, and are often good 


\section{Issues in Information Systems \\ Volume 20, Issue 4, pp. 107-115, 2019}

mediators in a teamwork environment which is common in ERP classes and in real-world working environment. As shown in Figure 2, individuals with both Openness trait and Agreeableness trait perform better than individuals with an extreme spectrum of Openness trait and Agreeableness trait. Individuals with a higher level of Openness and a lower level of Agreeableness have lower performance because those individuals may take too much time trying different things/approaches, are more paranoid and less willing to trust and work with others.

Table 1. ANOVA Results of Personality Traits on ERP Learning Performance Tests of Between-Subjects Effects

Dependent Variable: Course Grade Percentage

\begin{tabular}{|c|c|c|c|c|c|}
\hline Source & Sum of & df & Square & $\mathrm{F}$ & Sig. \\
\hline Corrected Model & $.356^{\mathrm{a}}$ & 25 & 0.014 & 1.223 & 0.225 \\
\hline Intercept & 0.010 & 1 & 0.010 & 0.900 & 0.344 \\
\hline Extraversion & 0.000 & 1 & 0.000 & 0.006 & 0.936 \\
\hline Agreeableness & 0.000 & 1 & 0.000 & 0.006 & 0.941 \\
\hline Conscientiousness & 0.002 & 1 & 0.002 & 0.211 & 0.647 \\
\hline Neuoticism & 0.008 & 1 & 0.008 & 0.687 & 0.408 \\
\hline Openness & 0.070 & 1 & 0.070 & 5.998 & 0.015 \\
\hline Agreeableness $\times$ Conscientiousness & 0.007 & 1 & 0.007 & 0.597 & 0.441 \\
\hline Extraversion x Agreeableness & 0.005 & 1 & 0.005 & 0.412 & 0.522 \\
\hline Agreeableness $x$ Openness & 0.049 & 1 & 0.049 & 4.221 & 0.041 \\
\hline Agreeableness $x$ Neuoticism & 0.004 & 1 & 0.004 & 0.311 & 0.578 \\
\hline Extraversion $x$ Conscientiousness & 0.014 & 1 & 0.014 & 1.203 & 0.274 \\
\hline Conscientiousness x Openness & 0.014 & 1 & 0.014 & 1.190 & 0.277 \\
\hline Conscientiousness $\times$ Neuoticism & 0.001 & 1 & 0.001 & 0.116 & 0.733 \\
\hline Extraversion x Openness & 0.040 & 1 & 0.040 & 3.456 & 0.065 \\
\hline Extraversion x Neuoticism & 0.002 & 1 & 0.002 & 0.150 & 0.699 \\
\hline Neuoticism x Openness & 0.014 & 1 & 0.014 & 1.206 & 0.274 \\
\hline $\begin{array}{l}\text { Extraversion x Agreeableness } x \\
\text { Conscientiousness }\end{array}$ & 0.057 & 1 & 0.057 & 4.930 & 0.028 \\
\hline Agreeableness $\times$ Conscientiousness $\times$ Openness & 0.022 & 1 & 0.022 & 1.902 & 0.170 \\
\hline Agreeableness $\times$ Conscientiousness $\times$ Neuoticism & 0.002 & 1 & 0.002 & 0.140 & 0.709 \\
\hline Extraversion x Agreeableness $x$ Openness & 0.062 & 1 & 0.062 & 5.342 & 0.022 \\
\hline Extraversion $x$ Agreeableness $x$ Neuoticism & 0.000 & 1 & 0.000 & 0.024 & 0.876 \\
\hline Agreeableness $\times$ Neuoticism $\times$ Openness & 0.001 & 1 & 0.001 & 0.069 & 0.794 \\
\hline Extraversion $x$ Conscientiousness $\times$ Openness & 0.001 & 1 & 0.001 & 0.054 & 0.817 \\
\hline Extraversion $x$ Conscientiousness $x$ Neuoticism & 0.014 & 1 & 0.014 & 1.191 & 0.277 \\
\hline Conscientiousness $\mathrm{x}$ Neuoticism $\times$ Openness & 0.011 & 1 & 0.011 & 0.948 & 0.332 \\
\hline Extraversion x Neuoticism x Openness & 0.000 & 1 & 0.000 & 0.006 & 0.936 \\
\hline Error & 2.087 & 179 & 0.012 & & \\
\hline Total & 149.731 & 205 & & & \\
\hline Corrected Total & 2.443 & 204 & & & \\
\hline
\end{tabular}

a. $\mathrm{R}$ Squared $=.146$ (Adjusted $\mathrm{R}$ Squared $=.027$ )

* significant at $\alpha=0.05$ level $\quad * *$ significant at $\alpha=0.10$ level

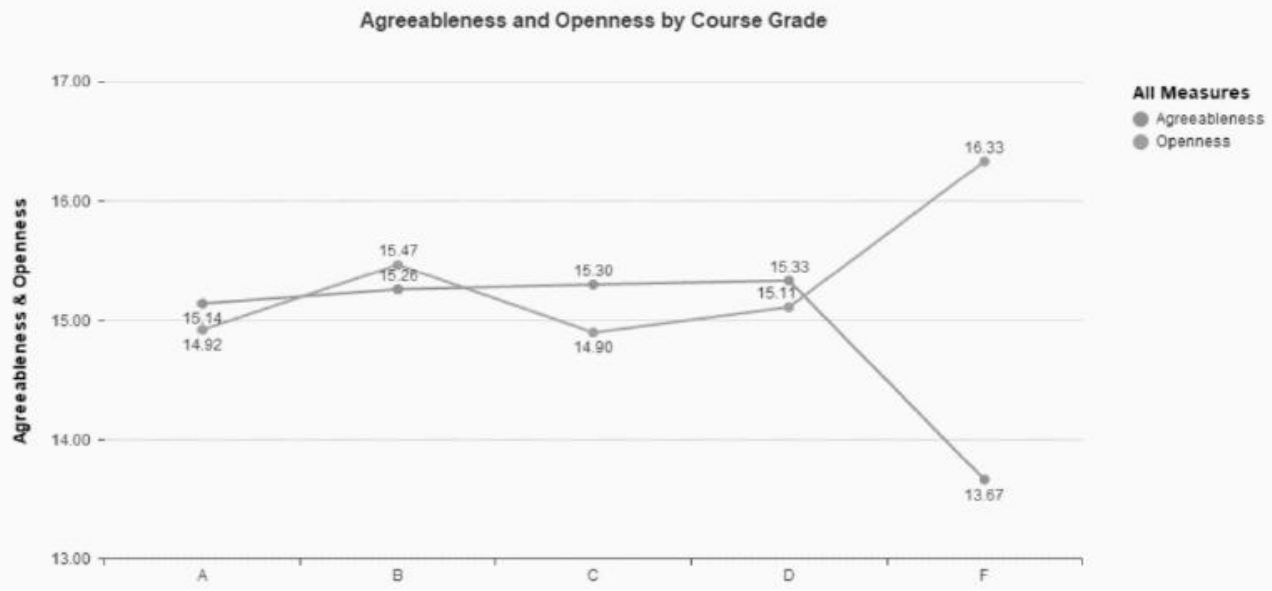

Figure 2. Impact of Openness and Agreeableness on Course Grade 


\section{Issues in Information Systems}

Volume 20, Issue 4, pp. 107-115, 2019

\section{Openness and Extraversion}

Individuals with a higher degree of Extraversion tend to be more approachable and sociable, more attention- and excitement-seeking, and more likely to participate in class. Extraversion predicts better learning when rewards are used to facilitate learning (Pickering, 2004; Robinson, et al., 2010). However, too much of Extraversion can get annoying and may too focus on social life and, thus, negatively related to academic performance (Chamorro-Premuzic \& Furnham, 2003; Nguyen et al., 2005). On the other side, individuals with a lower degree of Extraversion tend to exhibit detached coldness, social withdrawal, and anhedonia.

DeYoung (2006) proposed Plasticity, composed of openness to experience and extraversion, as a higher-order factor that reflects a tendency "to explore and engage flexibly with novelty, in both behavior and cognition." As shown in Figure 3, results of this study indicate that individuals with a moderate degree of both Openness and Extraversion perform better in learning ERP systems than individuals with a higher degree of Openness and a lower degree of Extraversion.

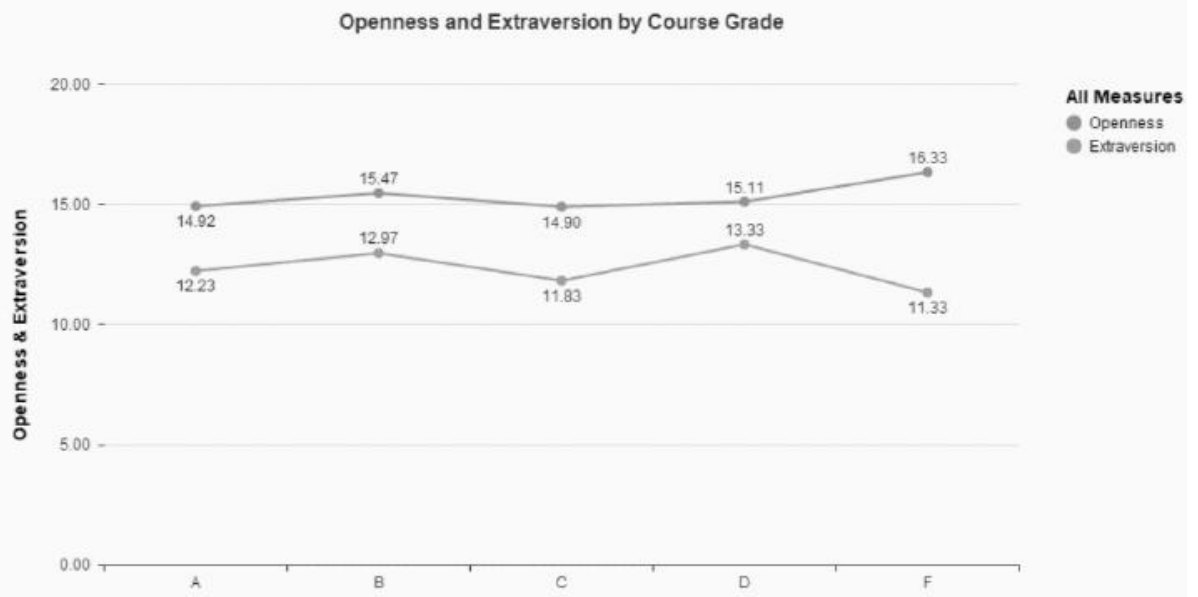

Figure 3. Impact of Openness and Extraversion on ERP Learning Performance

\section{Agreeableness, Extraversion, and Openness}

As shown in Figure 4, individuals with a more consistent and moderate degree of Openness and Agreeableness and a lower degree of Extraversion perform better than individuals with more extreme and inconsistent traits of Openness, Agreeableness, and Extraversion. One of possible causes of lower performance in learning ERP is that such individuals may be trying too many new approaches/ideas, are more introverted, detached, and socially withdrawal, and are less willing to compromise. Furthermore, results of this research suggest that a moderate degree of Extraversion can be essential. For example, too much extraversion can be seen as too much and result in the person not being taken seriously. A moderate Extraversion coupled with Openness helps to give a warm vibe to coax out ideas from teammates, so people are not afraid to give new ideas even if the idea seems irrelevant

\section{Agreeableness, Extraversion, and Conscientiousness}

As shown in Figure 5, individuals with a more consistent and moderate degree of Agreeableness and Conscientiousness and a moderate degree of Extraversion perform better than individuals with more extreme and less consistent of those three traits. Contentiousness trait reflects the tendency to be self-disciplined and organized and such individuals tend to work hard, be punctual, be more concerned with details and rules, and avoid distractions (DeYoung 2018). Although prior researches reported that Contentiousness and Agreeableness positively related to the academic learning performance (Paunonen \& Ashton, 2001; Laidra et al., 2007), the results of this study further indicated that a relatively higher degree of Agreeableness than Conscientiousness tends to result in a better performance. Furthermore, individuals with a relatively higher degree of Conscientiousness than Agreeableness and a relatively low degree of Extraversion tend to have lower performance in learning ERP system. One of the possible causes is that such individuals may be too concerned with details and rules (too "by the book"), too detached and socially withdrawal, and more paranoid to trust and work with others. On the other hand, learning ERP system often requires individuals to have the ability to "think out of the box," the willingness to try new approaches and ideas, and 


\section{Issues in Information Systems}

Volume 20, Issue 4, pp. 107-115, 2019

the ability to work with people from different business functions due to the complexity of ERP System, the interconnectivity and integration of different business functions, and the lack of understanding of business processes.

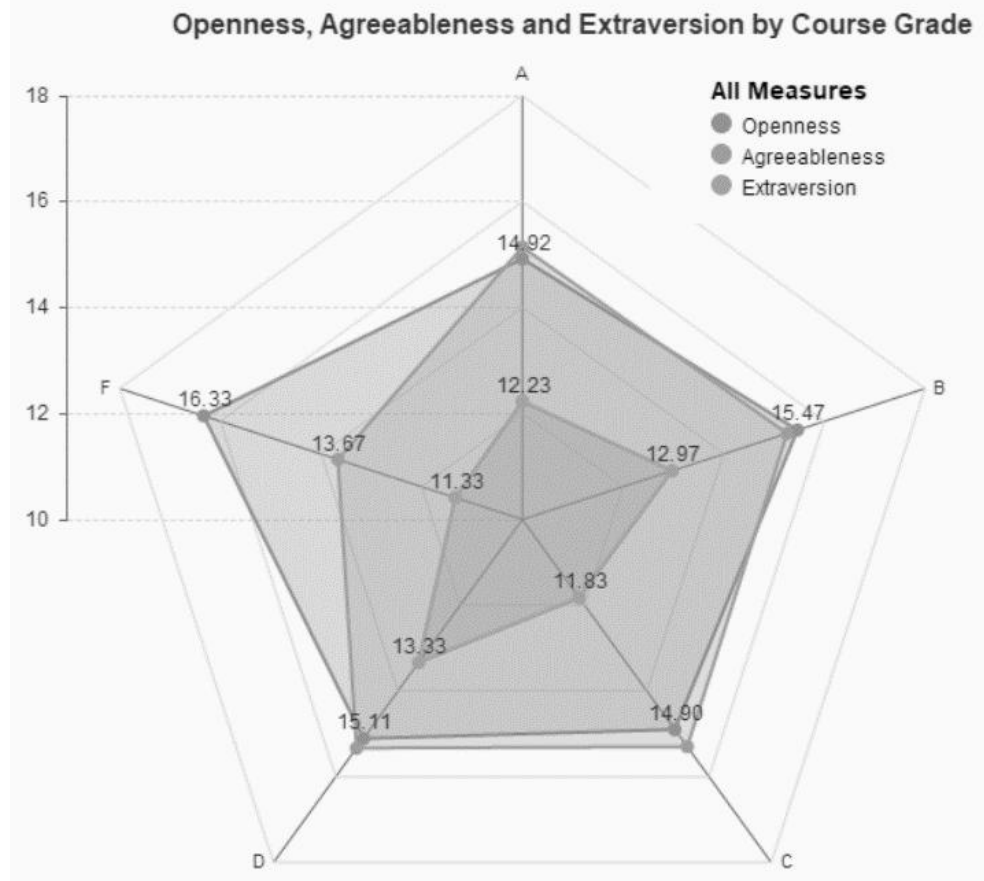

Figure 4. Impact of Openness, Agreeableness, and Extraversion on ERP Learning Performance

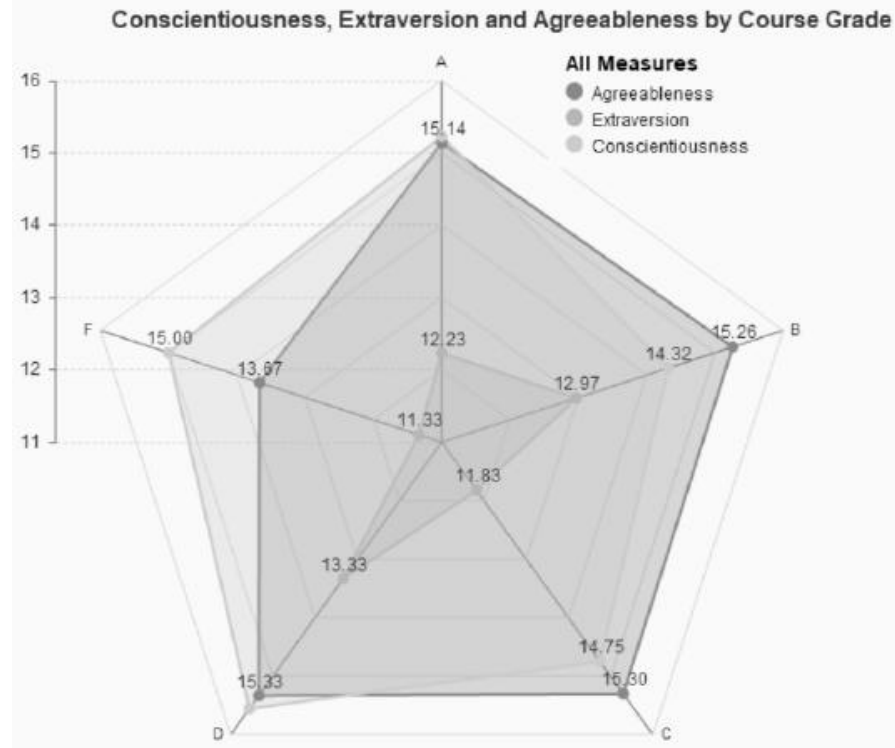

Figure 5. Impact of Agreeableness, Extraversion, and Conscientiousness on ERP Learning Performance

\section{SUMMARY AND FUTURE RESEARCH DIRECTIONS}


The objective of this research is to seek insights if there is an individual personality trait or an ideal combination of the Big Five personality traits that predict success in learning ERP systems and concepts. The results indicated that Openness, the interaction of Openness and Agreeableness, the interaction of Openness, Agreeableness, and Conscientiousness, the interaction of Openness, Agreeableness, and Extraversion, and the interaction Openness and Extraversion are statistically significant on influencing ERP learning performance. The results are summarized in Figure 6.

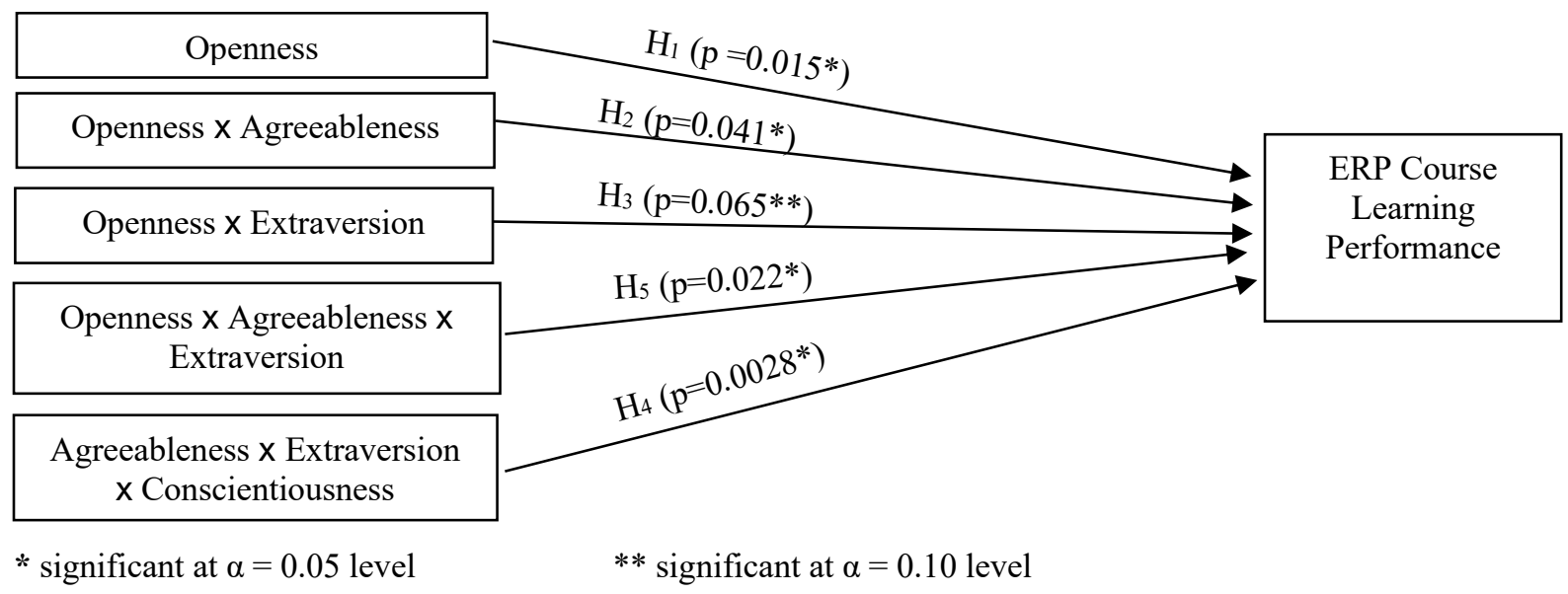

Figure 6. Summary of Results

Specifically, results of this study indicate that characteristics of Openness trait such as being receptive to new ideas, willing to take challenges, and resourceful have a positive influence in learning unfamiliar and complex ERP concepts and systems. Furthermore, the helpfulness, cooperativeness, and sympathetic characteristics of the Agreeableness trait and the sociability, attention-pursuing, and excitement-seeking characteristics of the Extraversion trait can further improve learning performance of students with a positive Openness trait. However, results of this study also indicate that students on an extreme end of the spectrum in one or more of those three personality traits (i.e., Openness, Agreeableness, and Extraversion) had lower performance than students that were more balanced. Results of this study also indicate that the degree of self-discipline, determination, purposefulness, and dependability characteristics of the Conscientious personality trait can have positive influence on ERP learning performance when paired with Agreeableness trait and Extraversion trait.

With the interaction among various personality traits found in this study, studies that investigate the linear combination of personality traits (or personality types) instead of examining each personality trait individually can be valuable. Studies in examining demographic factors such as gender, ethnicity, year in school, and prior IT knowledge can also be valuable in providing additional insights to extend the research results. Additional studies that investigate effective learning strategies for each personality trait or a combination of personality traits are also important and valuable for both academic and industry practice.

\section{REFERENCES}

Boyle, T. A., \& Strong, S. E. (2006). Skill requirements of ERP graduates. Journal of Information Systems Education, 17(4), 403.

Barki, H., \& Pinsonneault, A. (2002). Explaining ERP implementation effort and benefits with organizational integration. Cahier du GReSI no, 2(01).

Buruk, P., Şimşek, Ö. F., \& Kocayörük, E. (2017). Higher-order Traits and Happiness in the Workplace: The Importance of Occupational Project Scale for the Evaluation of Characteristic Adaptations. The Journal of general psychology, 144(4), 245-263. 


\section{Issues in Information Systems}

Volume 20, Issue 4, pp. 107-115, 2019

Chamorro-Premuzic, T., \& Furnham, A. (2003). Personality predicts academic performance: Evidence from two longitudinal university samples. Journal of research in personality, 37(4), 319-338.

Charland, P., Leger, P., Cronan, T. P., \& Robert, J. (2015). Developing and Assessing ERP Competencies: Basic and Complex Knowledge. Journal of Computer Information Systems, 56(1), 31-39.

Davies, S. E. (2014). Lower and higher order facets and factors of the interpersonal traits among the Big Five: Specifying, measuring, and understanding extraversion and agreeableness.

De Raad, B., \& Schouwenburg, H. C. (1996). Personality in learning and education: A review. European Journal of Personality, 10(5), 303-336.

DeYoung, C. G. (2006). Higher-order factors of the Big Five in a multi-informant sample. Journal of Personality and Social Psychology, 91(6), 1138.

DeYoung, C. G. (2015). Cybernetic big five theory. Journal of Research in Personality, 56, 33-58.

DeYoung, C. G., \& Krueger, R. F. (2018). A cybernetic theory of psychopathology. Psychological Inquiry, 29(3), $117-138$.

DeYoung, C. G., Peterson, J. B., \& Higgins, D. M. (2002). Higher-order factors of the Big Five predict conformity: Are there neuroses of health?. Personality and Individual differences, 33(4), 533-552.

Donnellan, M. B., Oswald, F. L., Baird, B. M., \& Lucas, R. E. (2006). The mini-IPIP scales: tiny-yet-effective measures of the Big Five factors of personality. Psychological assessment, 18(2), 192.

Ferguson, E., Semper, H., Yates, J., Fitzgerald, J. E., Skatova, A., \& James, D. (2014, 02). The 'Dark Side' and 'Bright Side' of Personality: When Too Much Conscientiousness and Too Little Anxiety Are Detrimental with Respect to the Acquisition of Medical Knowledge and Skill. PLoS ONE, 9(2).

Furnham, A. (1996). The FIRO-B, the learning style questionnaire, and the five-factor model. Journal of Social Behavior and Personality, 11(2), 285.

Gargeya, V. B., \& Brady, C. (2005). Success and failure factors of adopting SAP in ERP system implementation. Business Process Management Journal, 11(5), 501-516.

Grehan, P. M., Flanagan, R., \& Malgady, R. G. (2011). Successful graduate students: The roles of personality traits and emotional intelligence. Psychology in the Schools, 48(4), 317-331.

Klaus, H., Rosemann, M., \& Gable, G. G. (2000). What is ERP?. Information Systems Frontiers, 2(2), 141-162.

Komarraju, M., Karau, S. J., Schmeck, R. R., \& Avdic, A. (2011). The Big Five personality traits, learning styles, and academic achievement. Personality and Individual Differences, 51(4), 472-477.

Kumar, K., \& Van Hillegersberg, J. (2000). ERP experiences and evolution. Communications of the ACM, 43(4), $22-22$

Laidra, K., Pullmann, H., \& Allik, J. (2007). Personality and intelligence as predictors of academic achievement: A cross-sectional study from elementary to secondary school. Personality and Individual Differences, 42(3), 441-451.

Léger, P.-M. (2006). Using a Simulation Game to Teach Enterprise Resource Planning Concepts. Journal of Information Systems Education, 17(4), 441-447.

Lui, K. M., \& Chan, K. C. (2008). Rescuing troubled software projects by team transformation: A case study with an ERP project. IEEE Transactions on Engineering Management, 55(1), 171-184.

Markus, M. L., Axline, S., Petrie, D., \& Tanis, S. C. (2000). Learning from adopters' experiences with ERP: problems encountered and success achieved. Journal of Information Technology, 15(4), 245-265.

Morgeson, F. P., Reider, M. H., \& Campion, M. A. (2005). Selecting individuals in team settings: The importance of social skills, personality characteristics, and teamwork knowledge. Personnel Psychology, 58(3), 583-611.

Nguyen, N. T., Allen, L. C., \& Fraccastoro, K. (2005). Personality predicts academic performance: Exploring the moderating role of gender. Journal of Higher Education Policy and Management, 27(1), 105-117. 


\section{Issues in Information Systems}

Volume 20, Issue 4, pp. 107-115, 2019

Nelson, R. R., \& Cheney, P. H. (1987). Training end users: An exploratory study. MIS Quarterly, 11(4), 547-559.

Neuman, G. A., \& Wright, J. (1999). Team effectiveness: beyond skills and cognitive ability. Journal of Applied psychology, 84(3), 376.

O'Connor, M. C., \& Paunonen, S. V. (2007). Big Five personality predictors of post-secondary academic performance. Personality and Individual Differences, 43(5), 971-990.

Paunonen, S. V., \& Ashton, M. C. (2001). Big five factors and facets and the prediction of behavior. Journal of Personality and Social Psychology, 81(3), 524.

Pickering, A. D. (2004). The neuropsychology of impulsive antisocial sensation seeking personality traits: From dopamine to hippocampal function. On the psychobiology of personality: Essays in honor of Marvin Zuckerman, 453-476.

Poropat, A. E. (2009). A meta-analysis of the five-factor model of personality and academic performance. Psychological bulletin, 135(2), 322.

Riggio, R. E. (1986). Assessment of basic social skills. Journal of Personality and Social Psychology, 51(3), 649.

Robinson, M. D., Moeller, S. K., \& Ode, S. (2010). Extraversion and reward-related processing: Probing incentive motivation in affective priming tasks. Emotion, 10(5), 615.

Seethamraju, R. (2011). Enhancing Student Learning of Enterprise Integration and Business Process Orientation through an ERP Business Simulation Game. Journal of Information Systems Education, 22(1), 19-29.

Shtub, A. (2001). A framework for teaching and training in the Enterprise Resource Planning (ERP) era. International Journal of Production Research, 39(3), 567-576.

Sumner, M., Watson, E., \& Corbitt G. (2006). ERP Competencies: What Does Industry Need? Proceedings of the Americas Conference on Information Systems (AMCIS).

Tenhiälä, A., \& Helkiö, P. (2015). Performance effects of using an ERP system for manufacturing planning and control under dynamic market requirements. Journal of Operations Management, 36, 147-164.

Wadate, J. D. (2014). Enterprise Resource Planning (ERP) in Universities. International Journal of Informative \& Futuristic Research (IJIFR) 2.

Wodarski, J. S., Pippin, J. A., \& Daniels, M. (1988). The effects of graduate social work education on personality, values and interpersonal skills. Journal of Social Work Education, 24(3), 266-277. 